\title{
Secondary Flow Structures in Open Channel with Patchy Gravel and Vegetated Beds
}

\section{Folorunso OP*}

Department of Civil Engineering, Ekiti State University, Ado Ekiti, Nigeria

\begin{abstract}
Secondary flows are present in open channel due to the complex three-dimensional flow structures as a result of the existing natural features (e.g. different boundaries) affecting the flow. This paper experimentally examined the structure of secondary flow in open channel with a patchy gravel and vegetated beds using two different experimental conditions. A high resolution three-dimensional instantaneous velocity measurement over the gravel and vegetated bed were made using the acoustic Doppler velocimeter (ADV) and the secondary flow quantities determined. The results reveal that the magnitude of secondary flow over the gravel bed in experiment one is relatively large with occurrence of down-flow, and up-flow over the flexible vegetated bed. The lateral interaction and momentum transfer between the two-bed roughness (gravel and vegetated beds) is achieved by the secondary flow, at the lower region of the flow, the transverse motion is directed from the gravel bed towards the grass bed, and at the upper region, and the flow is transported laterally in the opposite direction.
\end{abstract}

Keywords: Velocity; Secondary flow; Momentum; Transport; Gravel; Grass; Open channel

\section{Introduction}

Bed roughness is typical of natural rivers; its variability is an important characteristic in open channel flow as this affects the hydrodynamic behaviour of flow. Modelling this behaviour is important in the evaluation of flow characteristics in open channels for meaningful hydraulic predictions and flood management such as conveyance capacity, mass and momentum transfer for effective design of river engineering infrastructures, provision of flood warnings and the protection of biodiversity. Transport characteristics of natural rivers have been shown to be dependent on the bed roughness [1] and by extension provides potential for the exchange of resources between ecological habitats in aquatic environment.

Secondary currents are present in open channels, depending on the flow conditions. They can be classified into two categories [2]. The first kind of Prandtl's secondary flow is the one generated due to the irregular shape of the channels. The mean flows in such channels are skewed due to curves and bends. This type of secondary flow can often be found in both laminar and turbulent conditions. The second kind of Prandtl's secondary flows are those generated by the cross-sectional shape and corresponding non-homogeneity of turbulence due to channel boundaries. They are also known as the shear or turbulence driven secondary currents.

The lateral flow $v$ and $w$ in a straight channel are governed by the vorticity () equation [3]:

$$
\begin{aligned}
& v \frac{\partial \Omega}{\partial y}+w \frac{\partial \Omega}{\partial z}=\frac{\partial^{2}}{\partial y \partial z}\left(\overline{v^{\prime 2}}-\overline{w^{\prime 2}}\right)+\left(\frac{\partial^{2}}{\partial z^{2}}\right) \overline{v^{\prime} w^{\prime}}+v \nabla^{2} \Omega \\
& \Omega=\frac{\partial w}{\partial z}-\frac{\partial v}{\partial y}
\end{aligned}
$$

The vorticity Equation (1) accurately governs the secondary motions in open channels [3].

In a more detailed flume experiment, Nezu and Nakagawa [4] observed in an open channel with a rectangular cross-section that the aspect $\operatorname{ratio}(\mathrm{B} / \mathrm{H})(\mathrm{B}$ is the channel width and $\mathrm{H}$ is the depth of flow) determines the magnitude of the secondary flow. For open channels, Nezu and Nakagawa set a limit of aspect ratio of 5 to be critical value below which the secondary currents extends to the centre and thereby affect the whole channel. For values of $(\mathrm{B} / \mathrm{H})>5$ the secondary current is dampen thereby the central part of the channel is unaffected. The central part is defined by [5]:

$$
\left|\frac{y^{\prime}}{H}\right| \leq \frac{\left[\frac{B}{H}-\left(\frac{B}{H}\right)_{\text {crit }}\right]}{2}
$$

Where defines the lateral distance from the centre of the channel. Using the critical value of aspect ratio, open channel is classified into two categories: Narrow $\left(\frac{B}{H}<5\right)$ and Wide $\left(\frac{B}{H}<5\right)$ open channels [3].

Turbulence driven secondary flows are initiated by the effects of the sidewall and the bed roughness [6], and later extended in lateral direction to the central region for narrow $\left(\frac{B}{H}<5\right)$ channels. In wide channels, the magnitude of the corner vortices energy can reduce rapidly. This allows the central region of the channel to be free from the effects of secondary currents. These flows phenomenal have been investigated by Nezu and Nakagawa [3]; considered to be responsible for the velocity dip in open channels; this is the location of the maximum velocity in the vertical section below the free surface instead of at the free surface [3].

Figure 1 illustrates the flow pattern of cellular secondary currents in $\left(v^{\prime}, w^{\prime}\right)$ an open channel flow with $\left(\frac{B}{H}=6.0\right)$, using X-type hot films [4]. A pair of cellular secondary currents can be seen clearly with the upflow and downflow moving in circular motion.

The work will investigate the influence that rigid vegetation (akin to 'shrubs') and flexible vegetation (akin to 'grass') have on secondary flow generation within an idealized open channel with a patchy roughness

*Corresponding author: Folorunso OP, Department of Civil Engineering, Ekiti State University, Iworoko road, Ado Ekiti, Ekiti State, Nigeria, Tel: 08085503802; E-mail: ftobex@ymail.com

Received January 06, 2018; Accepted February 22, 2018; Published February 28, 2018

Citation: Folorunso OP (2018) Secondary Flow Structures in Open Channel with Patchy Gravel and Vegetated Beds. J Civil Environ Eng 8: 303. doi: 10.4172/2165784X.1000303

Copyright: (c) 2018 Folorunso OP. This is an open-access article distributed under the terms of the Creative Commons Attribution License, which permits unrestricted use, distribution, and reproduction in any medium, provided the original author and source are credited. 
distribution, this will help to determine the variability of momentum transport and mechanisms responsible due to changes in roughness characteristics for river management.

\section{Materials and Methods}

The experiments were conducted in $22 \mathrm{~mm}$ long rectangular recirculating flume of width $\mathrm{B}=614 \mathrm{~mm}$ at the University of Birmingham. The channel is supplied from a constant head tank with a capacity of $45,000 \mathrm{l}$ in the laboratory roof. A flow discharges $(Q)(30.0 \mathrm{l} / \mathrm{s})$ with corresponding flow depth $(H)$ of $130 \mathrm{~mm}$ width to depth ratio $(B / H)$ of 4.7 achieve subcritical flow condition was investigated. In what follows these experimental conditions are referred to as EXPT1 and EXPT2 respectively. Detailed velocity measurements were made at three cross sections (CRS1, CRS2 and CRS3) at distances of $17.5 \mathrm{~m}, 17.85 \mathrm{~m}$ and $18.2 \mathrm{~m}$ respectively downstream from the channel inlet. In the results that follow, the gravel region of the bed extends over $\left(0.5 \leq \frac{y}{B} \leq 1.0\right)$ , the interface occurs at $(y / \mathrm{B}=0.5)$, and the vegetated region extends over $\left(0.5 \leq \frac{y}{B} \leq 1.0\right)$, where $y$ is the lateral distance from the left hand side looking downstream and $B$ is the channel width. The streamwise direction $x$ is in the direction of flow. The transverse direction $y$ is perpendicular to $\mathrm{x}$ in the lateral direction, while the vertical direction is denoted by $z$ and is perpendicular to the $x y$ plane (positive upwards). The corresponding time average velocity components are $u, v, w$ respectively. Figure 2 shows the bed configuration for EXPT1 and EXPT2.

Velocity data were collected in $10 \mathrm{~mm}$ by $10 \mathrm{~mm}$ grid spacing in the plane at the three cross-sections (CRS1, CRS2 and CRS3) with the first measurement taken at $10 \mathrm{~mm}$ above the channel bed (within the sampling volume of the Vectrino). The spacing grid was adopted in order to represent a trade-off between making the measurement within the time frame and achieving a high resolution. Because of the influence of the channel walls on the ADV's performance, measurements with the $\mathrm{ADV}$ were undertaken up to $30 \mathrm{~mm}$ to the channel side walls.

\section{Results and Discussion}

Secondary flow vectors were obtained by calculating $\left(V^{2}+W^{2}\right)^{\frac{1}{2}}$, where $\mathrm{V}$ and $\mathrm{W}$ are the mean lateral and vertical velocities respectively, the results of which are shown in Figures 3 and 4 . As a check, these values were numerically integrated over the cross section and the resultant velocities were found to be closed to zero, for example $\left(3.33 \times 10^{-3}\right)$. The maximum calculated mean vector is within $3 \%$ of the mean stream wise velocity $(U)$ for both EXPT1 and EXPT2 and as such is in keeping with the values found elsewhere [3,7,8]. Figures 3 and 4 illustrate the distributions of the secondary flow vectors. Based on these figures it can be seen that CRS2 and CRS3 show more definite vector directions relative to CRS1 because the flow structures begin to stabilize as the distance from the change in roughness increases due to downstream development of the flow.

For EXPT1 Figure 3, the direction of the secondary flow vector is similar to those observed for rough and smooth strips by Jesson et al. [7], Wang and Cheng [8], and Vermaas [9]. A visual inspection shows that the magnitude of secondary flow over the gravel bed $\left(0.5 \leq \frac{y}{B} \leq 1.0\right)$ in EXPT1 is relatively large with occurrence of down-flow, and upflow over the flexible vegetated bed $\left(0.5 \leq \frac{y}{B} \leq 1.0\right)$. At the lower region $\left(\frac{z}{H} \leq 0.2\right)$ of the flow, the transverse motion is directed from the gravel bed towards the flexible vegetated bed, and at the upper region $\left(\frac{z}{H}>0.2\right)$, the flow tends to be transported laterally in the opposite direction (although it is acknowledged that interpretation of secondary flow vectors is not definitive of the flow's actual behavior). The direction of the flow vectors indicates a transfer of low momentum fluid from the vegetated region to the gravel region. The boundary region $(y / B=0.5)$ is apparently characterized by downflow into the vegetated bed. It can be seen from Figure 3 that, the secondary flow moves upward the near bed low velocity fluid due to resistance of the vegetated region and transport same to the gravel region near the free surface, whilst on the gravel side downflow occurs which transport the high velocity fluid near the free surface down the lower portion of the flow, at this region the flow is transported laterally into the vegetated region. The up flow over the vegetated bed $\left(0.5 \leq \frac{y}{B} \leq 1.0\right)$ is induced by the retardation of the near

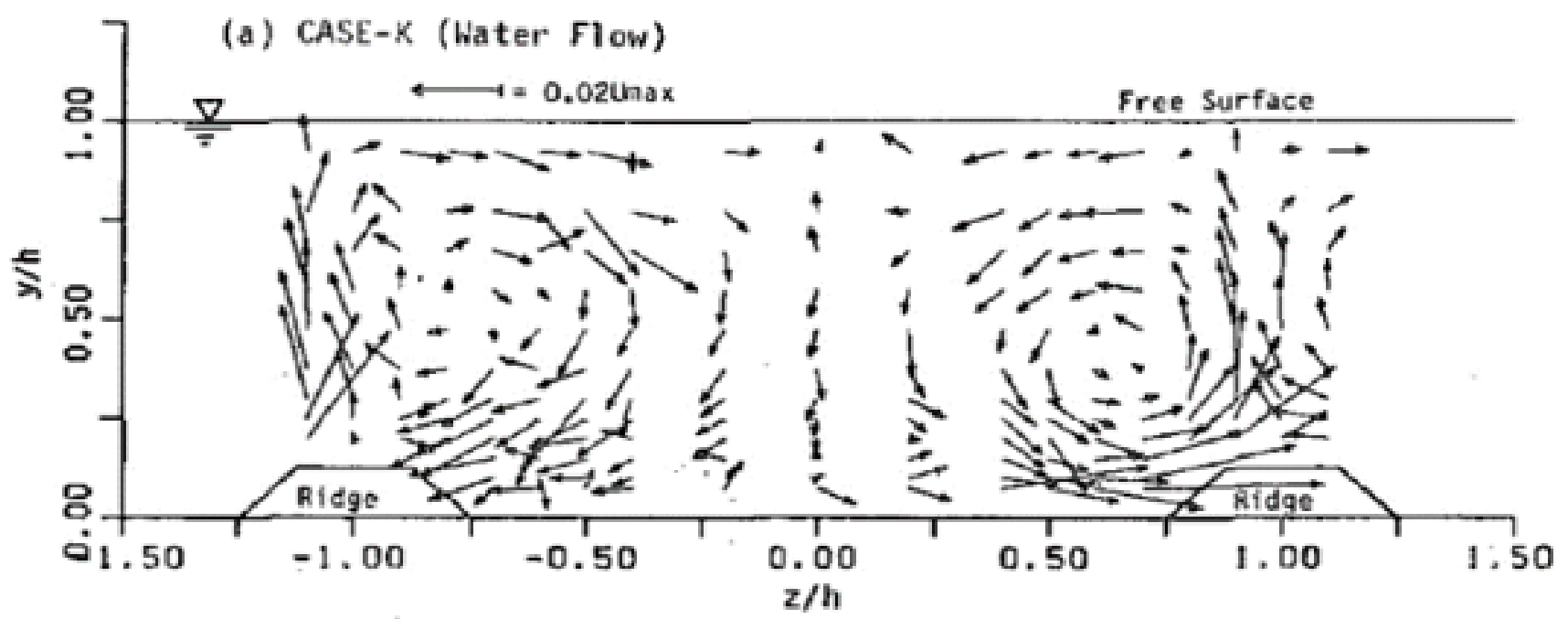

Figure 1: Flow pattern of cellular secondary currents in water Channel (Nezu and Nakagawa, 1984). 
Citation: Folorunso OP (2018) Secondary Flow Structures in Open Channel with Patchy Gravel and Vegetated Beds. J Civil Environ Eng 8: 303 . doi: 10.4172/2165-784X.1000303

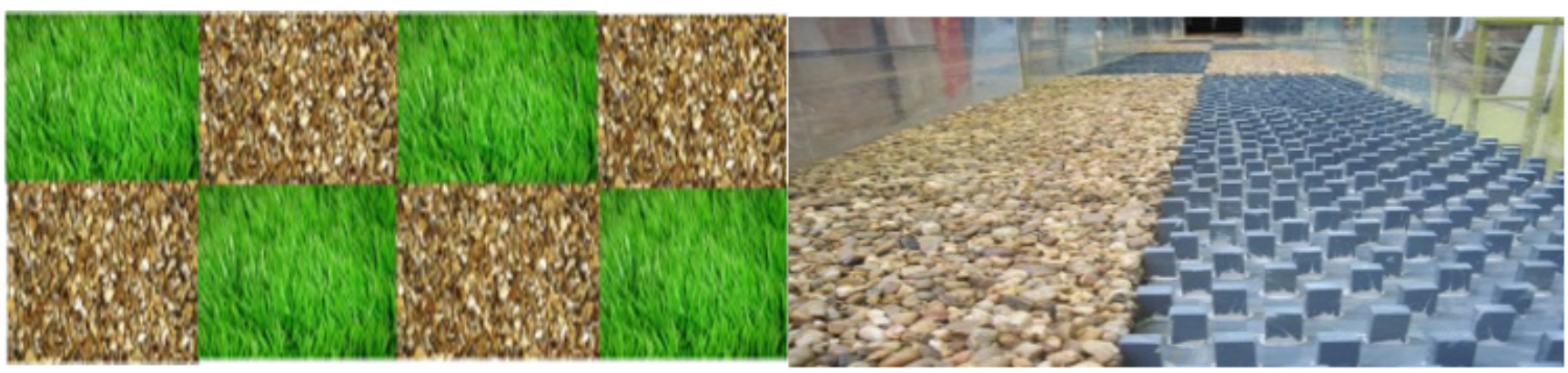

Figure 2: Bed roughness configuration plan view of roughness patches for experiment one and two.
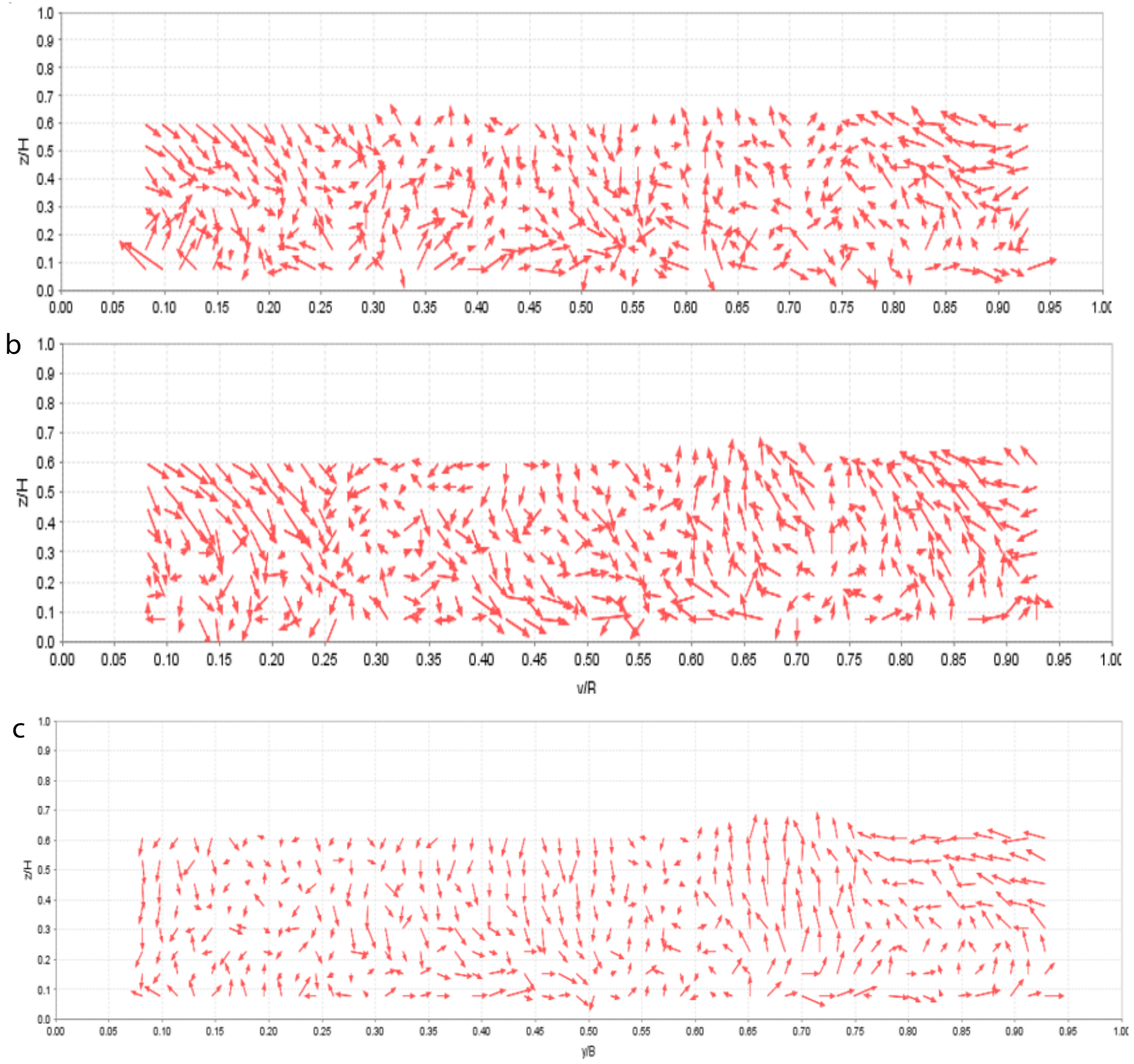

Figure 3: Lateral flow distributions (EXPT1) CRS1 (top) to CS3 (bottom) 
Citation: Folorunso OP (2018) Secondary Flow Structures in Open Channel with Patchy Gravel and Vegetated Beds. J Civil Environ Eng 8: 303 . doi: 10.4172/2165-784X.1000303

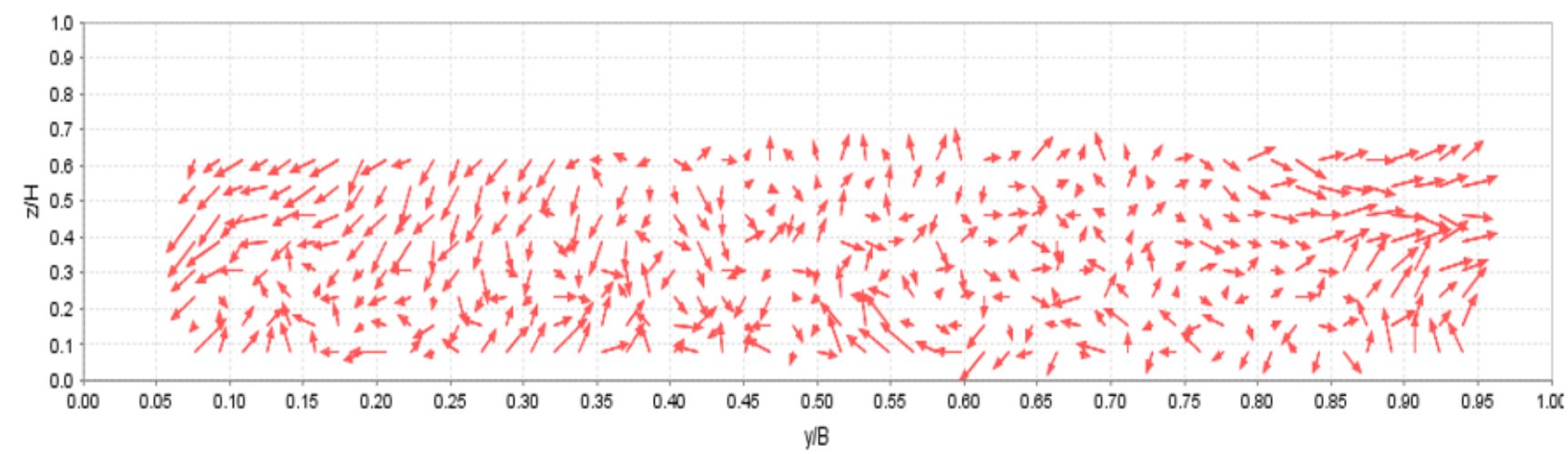

A

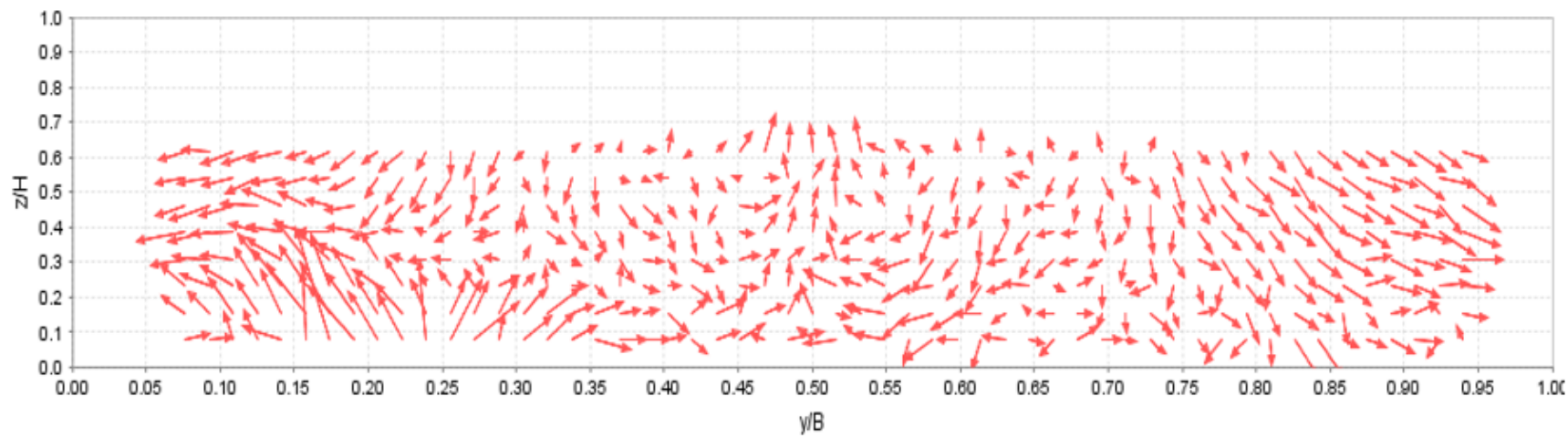

B

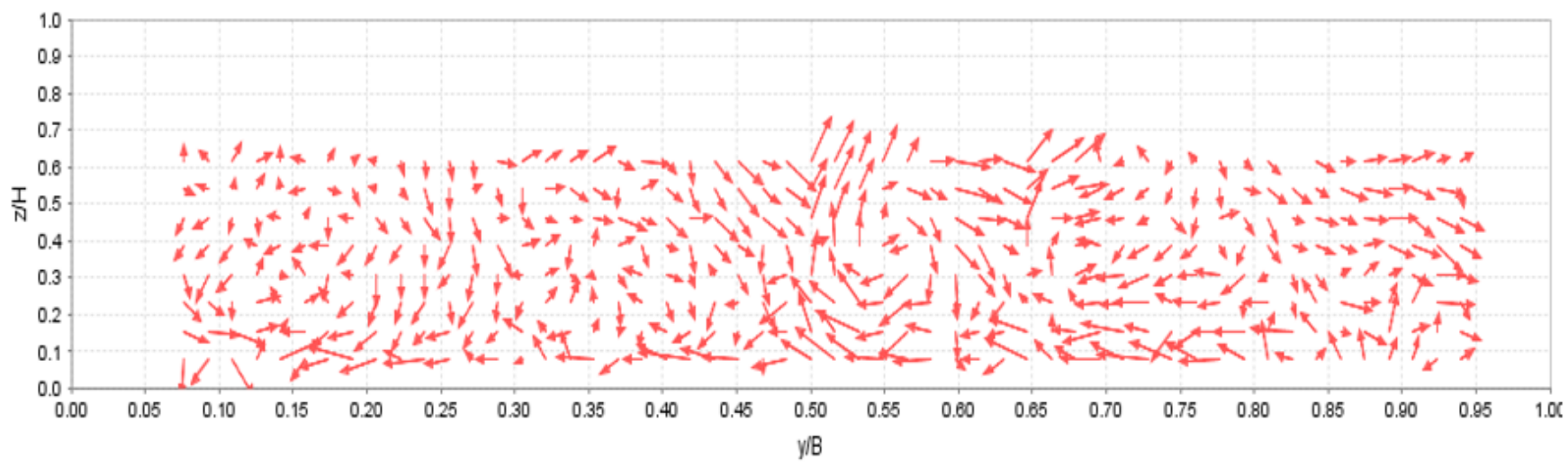

C

Figure 4: Lateral flow distributions (EXPT2) CRS1 (top) to CS3 (bottom).

bed stream wise flow due to vegetation stem density. It will be noted that due to the bed configuration, a relatively higher velocity will flow from the previous gravel bed to the new vegetated bed where the flow velocity is retarded - continuity suggests that the low velocity fluid is therefore transported upward by the secondary flow and direct towards the gravel region. This feature is consistent for all the cross-sections as indicated in Figure 3. 
The secondary flow vectors in EXPT2 (CRS3) however suggests the appearance of the developing secondary flow cells moving in clockwise direction over the gravel bed $\left(0 \leq \frac{y}{B} \leq 0.5\right)[4,6,7,10,11]$ with the circulation demonstrating strong up-flow at the roughness boundary $(y / B=0.5)$ (Figure 4), the flow cells in clockwise direction appear to dominate momentum transfer between the gravel and vegetated bed strips (Figure 4). This suggests that, the contribution of the secondary flow is significant at the roughness boundary region in EXPT2. However, the results indicate evidence of downflow over both roughness regions. The directions and circulations of these secondary vectors are consistent along the channel CRS2 and CRS3.

The lateral distribution of the streamwise velocity over the vegetated bed region in EXPT1 (results not shown) corresponds to the region of upflow in Figure 3. In this region $\left(0.6 \leq \frac{y}{B} \leq 0.9\right)$, the mean flow decelerates near bed. The mean streamwise velocity increases towards the free surface at approximately $\left(0.2 \leq \frac{y}{B} \leq 0.5\right)$ which forms the region of downflow over the gravel region as evidenced in Figure 3. In EXPT2 the minimum mean streamwise velocity at the boundary region $(y / B=$ 0.5) (results not shown) corresponds to the region of upflows in Figure 4. This is consistent with the findings of Jesson et al. [7] who observed the existence of the relatively strong upflows near the rough-smooth boundary.

\section{Conclusion}

The measured secondary flow values have been normalized by theoretical velocity to make it dimensionless in order to compare and contrast the secondary flow distribution for all locations. Moreover the width and depth of the channel were normalized by the overall depth and width of the channel respectively. The velocities were measured with a accuracy and deviations.

The direction of the flow vectors indicates a transfer of low momentum fluid from the vegetated region to the gravel region. The boundary region $(y / B=0.5)$ is apparently characterized by downflow into the vegetated bed. The lateral interaction is achieved by the secondary flow, at the lower region $\left(\frac{z}{H} \leq 0.2\right)$ of the flow, the transverse motion is directed from the gravel bed towards the grass bed, and at the upper region $\left(\frac{z}{H} \leq 0.2\right)$, the flow is transported laterally in the opposite direction in EXPT1 (Figures 3). The secondary vector in EXPT2 suggests the appearance of developing cells circulating in clockwise direction as illustrated in Figure 4. In addition, the upward flow over the vegetated bed in EXPT1 (Figure 3) can be attributed to the flow retardation and pressure around the vegetation stems due to high stem density.

\section{References}

1. Shafi HS, Antonia RA, Krogstad PA (1997) Heat flux measurements in a turbulent boundary layer on a rough wall. Int J Heat Mass Transfer 40: 29892993.

2. Prandtl L (1952) Essentials of fluid dynamics. Springer, Amsterdam.

3. Nezu I, Nakagawa H (1994) Turbulence in open-channel flows. J Hydraul Eng 120: $1235-1237$

4. Nezu I, Nakagawa H (1984) Cellular secondary currents in straight conduit. J Hydraul Eng 110: 173-193.

5. Jesson M, Sterling M, Bridgeman J (2010) Turbulent structures in heterogenous channels and their effects on conyeyance. first lahr European Div Congress International Association for Hydro-Environment Engineering and Research (lahr), Madrid, Spain.

6. Wang ZQ, Cheng NS (2005) Secondary flows over artificial bed strips. Adv Water Resour 28: 441-450.

7. Jesson M, Sterling M, Brigdeman J (2013) Modelling flow in an open channel with heterogeneous bed roughness. J Hydraul Eng 139: 195-204.

8. Wang ZQ, Cheng NS (2006) Time-mean structure of secondary flows in open channel with longitudinal bedforms. Adv Water Resour 29: 1634-1649.

9. Vermaas DA, Uijttewaal WSJ, Hoitink AJF (2011) Lateral transfer of streamwise momentum caused by a roughness transition across a shallow channel. Water Resour Res 47: 2.

10. Jesson M, Sterling M, Bridgeman J (2012) An experimental study of turbulence in a heterogeneous channel. Proceedings of the Institution of Civil EngineersWater Management 166: 16-26.

11. Knight DW, Omran M, Tang X (2007) Modeling depth-averaged velocity and boundary shear in trapezoidal channels with secondary flows. J Hydraul Eng 133: 39-47. 